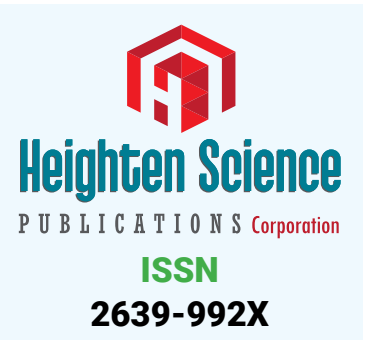

*Address for Correspondence: Mokrushin AA, I.P, Pavlov Institute of Physiology, Russian Academy Science, Saint-Petersburg, Russia, Email: mok@inbox.ru

Submitted: 14 June 2017

Approved: 06 July 2017

Published: 07 July 2017

Copyright: @ 2017 Durisova M. This is an open access article distributed under the Creative Commons Attribution License, which permits unrestricted use, distribution, and reproduction in any medium, provided the original work is properly cited

Keywords: Synaptic plasticity; Glun1 subunit Oligodeoxynucleotides

Abbreviations: aCSF: artificial Cerebrospinal Fluid; LOT: Lateral Olfactory Tract; FP: Field Potential; EPSP: Excitatory Postsynaptic Potential; NMDAR: N-methyl-D-aspartate Receptors; AMPAR: Alpha-amino-3-hydroxy-5methyl-4-isoxazolepropionic Receptors; GluN1 Subunit of the NMDAR; LTP/LTD: Long-term potentiation/depression; ODNs: Antisense and Sense Oligodeoxynucleotides

Check for updates
Research Article

\section{Sense and antisense}

Oligodeoxynucleotides to Glun1

Nmdar are Cognitive Enhancers

(Nootropics) and protective agents

in normal and ischemic (Anoxic)

conditions-In vitro study

\author{
Anatoly A Mokrushin* \\ Pavlov Institute of Physiology, Russian Academy Science, Saint-Petersburg, Russia
}

\section{ABSTRACT}

Aims: Implication of modified N-methyl-D-aspartate receptors (NMDAR) in synaptic plasticity and learning was investigated in normal and pathological conditions.

Study design: We studied the efficiency of synaptic plasticity, the development of the longterm potentiation/depression (LTP/LTD) in olfactory cortex slices, treated with antisense or sense oligodeoxynucleotides (aODNs and sODNs) to the GluN1 subunit of NMDAR.

Main outcome: aODNs induced the LTD development in slices after high-frequency tetanization. Contrariwise, in sliced treated with sODNs the enhanced LTP developed. Under conditions of severe anoxia (10 $\mathrm{min})$, treatment of slices with aODNs and SODNs contributed to the preservation of synaptic activity which has been blocked in the control untreated slices. In practical implications such directed up- and down regulation of NMDAR might be useful in the readjustment of brain activity by the controlling balance of excitation/inhibition.

\section{INTRODUCTION}

Regulation of cognitive processes, mainly their improvement is now an important aspect of the study of brain function. Activity-dependent, bidirectional control of synaptic efficacy is thought to contribute in many forms of experience-dependent plasticity, including learning and memory in normal and pathological conditions. Ionotropic glutamate receptors, specifically $N$-methyl-D-aspartate receptors (NMDAR) as well as alpha-amino-3-hydroxy-5-methyl-4-isoxazolepropionic receptors (AMPAR) play a main role in excitatory neurotransmission and involve in synaptic plasticity [1]. AMPAR are thought to be important for the expression of synaptic changes following the activation of the NMDAR [2]. NMDARs are heterotetramers composed of obligatory GluN1 subunit and one of regulatory subunits: GluN2 (A-D) or GluN3 (A-B) [3]. The GluN1 subunit have been shown to involved in synaptic plasticity [4-6]. Alterations in expression of synaptic GluN1 subunit of NMDARs resulted in modification of mechanisms underlying certain forms of learning $[7,8]$ and implicated in cognition dysfunctions especially in neurological disorders [9,10]. GluN1 subunit hypofunction is possibly connected with cognition defects [11]. Currently, enhancement of NMDARs function is regarded as an important goal for recovering of cognitive decline [12]. 
Antisense oligonucleotides (aODNs) have been used in various tissues as therapeutic agents, and as research tools for downregulating certain genes. Antisense transcripts specific for NMDAR subunits GluN1 resulted in reductions of GluN1 mRNA and protein expressions after intrastriatal administrations into rats $[13,14]$. The effects of aODNs for this subunit connected with reduction of NMDAR-induced excitability were demonstrated in models of Parkinson disease [15,16]. aODNs to GluN1 subunit produced an antinociceptive effect in mice [17-19] and exerted a protective effect in NMDAR-induced excitotoxic cell death in striatal neurons in vitro $[14,20]$. It was shown that genetic reduction of NMDARs (GluN1 knock-out) alters learning in mice [21], excitatory-inhibitory balance in model of schizophrenia [22,23] and resulted in aberrant behavior [24,25]. Synaptic expression of the NMDAR subunits is enhanced rapidly after the LTP induction in slices from adult rat hippocampus [26,27]. Moreover, high frequency stimulation induced then increase in cortical GluN1 subunit which was observed one and three weeks after training [28].

Despite foregoing observations, molecular and cellular mechanisms along with the known physiological and pharmacological effects of aODNs and sODNs are not clear. The aim of the current study was firstly to reveal whether these ODNs to GluN1 induces the changes in the activity of the NMDAR and AMPAR synaptic network in brain slices. Secondly, we investigated the dependence of LTP and, possibly long-term depression (LTD) from the up- and down regulation of GluN1 subunit. The influence of this regulation was tested under anoxia too. These data may elucidate the mechanism of the GluN1-dependent activity of NMDAR in normal and pathological conditions.

\section{METHODS}

\section{Animals and slice preparations}

All animals used in this study were treated with observance of recommendations on ethics of work with the animals offered European Communities Council Direction (86/609 EEC). The experiments with rats were approved in strict accordance with the Russian Federation Council's Guide for the Care and Use of Laboratory Animals (1994) and with the guidelines of the IP Pavlov Institute Physiology Russian Academy of Sciences of the ethical code (1996). Male Wistar rats (200-250 g, 4-5 month) were housed four per cage on a $12 \mathrm{~h}$ dark/ light cycle in a temperature-controlled environment with free access to food and water. All efforts were made to minimize animal suffering and reduce the number of animals used. Tangential slices of olfactory cortex about 400-500 $\mu \mathrm{m}$ in thickness prepared within 1 min were maintained in artificial cerebrospinal fluid (aCSF), consisted of (in mM): $124 \mathrm{NaCl}, 5 \mathrm{KCl}, 2.6 \mathrm{CaCl}_{2}$, $1.24 \mathrm{KH}_{2} \mathrm{PO}_{4}, 1.2 \mathrm{MgSO}_{4}, 3 \mathrm{NaHCO}_{3}, 10$ glucose, 23 Tris- $\mathrm{HCl}$ (Sigma, USA); equilibrated with $\mathrm{O}_{2}$, with osmolarity of $295-305 \mathrm{mOsm}$. The temperature was $37^{\circ} \mathrm{C}, \mathrm{pH}$ 7.2-7.3.

The use of Tris- $\mathrm{HCl}$ allowed us to conduct the experiments in an atmosphere of $\mathrm{O}_{2}$. Concentrations of $\mathrm{Ca}^{2+}$ and $\mathrm{Mg}^{2+}$ were optimized to retain a maximal synaptic activity in olfactory cortex for 10-12 h [29]. The automatically controlled rate of the slice perfusion along with a continuous delivery of oxygen was equal to $2 \mathrm{ml} / \mathrm{min}$. A complete exchange of the solution in the recording chamber occurred in about $1 \mathrm{~min}$. All chemical reagents used for incubation medium were from "ChimReactive", (Russia). In the series of experiments for studying the ODNs influence in anoxic condition, we used the replacement of oxygen supply to recording chamber for nitrogen during the slices incubation. Firstly, we compared the influence of $10 \mathrm{~min}$ anoxia on modifications of the NMDA EPSP amplitudes in slices treated with ODNs. Then we tested the proportion of potentiated slices after treatment with s/a ODNs after 10 min anoxia.

\section{Oligodeoxynucleotides treatment protocols}

We tested pharmacokinetic property of ODNs targeted to specific GluN1 subunits of NMDAR. Sense (5`- CTACAACGTACAAGTAGT -3') or antisense (5`- 
CAGCAGGTGCATGGTGCT -3') ODNs [30] to GluN1 subunits of NMDAR, obtained from custom-synthesized at GNC Vector (Novosibirsk, Russia), were dissolved in aCSF to $10 \mathrm{nM}$ concentration. The required time of the slices incubation with ODNs was determined to achieving the ODNs effects on modifications of the NMDA EPSP component of FPs. We found that the incubation of brain slices with ODNs during 270 min was already sufficient to achieve their persistent and sustained effects even after washing. For greater certainty, we used a longer period of incubation - $360 \mathrm{~min}$.

Studies were made of the effect of missense oligodeoxynucleotides, which were considered as control effects. It was found that missense oligodeoxynucleotides did not cause changes in AMPAR and NMDAR activity.

\section{Electrophysiological recordings}

Electrophysiological and pharmacological identification of AMPAR and NMDAR in piriform cortex of olfactory cortex slices allowed to analyzed evoked basal glutamatergic synaptic transmission and synaptic efficiency of NMDAR-dependent LTP or LTD after high frequency tetanization of the lateral olfactory tract (LOT) [29]. Briefly, the field potentials (FPs) were evoked using stimulating platinum bipolar electrodes with a tip separation of $0.5 \mathrm{~mm}$ positioned onto the proximal part of LOT-the main input of afferent impulses to neurons of olfactory cortex. The point of recording was located in this focus of maximal activity. Orthodromic stimulation of LOT imitated the flows of afferent impulses from the mitral neurons of the olfactory bulb in vivo. The rectangular pulses with duration of $0.1 \mathrm{msec}$ and the intensity of $1-3 \mu \mathrm{A}$ were evoked with aid of the constant current stimulator (ESU-1, Russia) through platinum custom-made bipolar concentric electrode insulated at the cut ends. The FPs from slices were recorded using a glass microelectrode. A tip resistance of microelectrode, filled with $1 \mathrm{M} \mathrm{NaCl}$ was 1-5 $\mathrm{M} \Omega$. FPs recordings were performed, using an NTO-2 amplifier (Russia). The reference silver electrode was located in a chamber floor.

\section{FPs processing}

The FPs were processed in the on-line mode after amplifying (NTO-2, Russia), and then were digitized with the analog-digital converter MD-32 (Russia) (sample rate $25 \mathrm{kHz}$ ) and transmitted to computer for registration and subsequent analysis using special homemade software. We estimated the amplitudes of FPs components from the isoline to the peak level. The amplitudes of AMPA EPSP we assessed within an 2 msec window centered at the peak of the response. Peak NMDA EPSP was measured as the average potential observed in an $8 \mathrm{msec}$ window [31]. At that time, FPs were recorded in response to electric stimulation with frequency $0.003 \mathrm{~Hz}$ during $15 \mathrm{~min}$ and referred as a control. Such electric stimulation was infrequent to eliminate the development of a habituation in olfactory neurons in answer to repeated stimulation. To make sure the authenticity of NMDA EPSP components of FPs in all series of experiments we used competitive blocker of the ionotropic NMDAR - D-2-amino-5phosphonovalerate (D-APV, "Sigma"(USA); a competitive antagonist of NMDAR). For the NMDA EPSP isolation we applied $50 \mu \mathrm{M}$ of D-APV. In every experiment the FPs were recorded in response to stimulation of the LOT proximal part before and after perfusion with D-APV to isolate the NMDAR activation.

For LTP/LTD induction we employed fourfold high frequency tetanization of the LOT fibers: potentiating trains consisted of 10 sets of four pulses at $100 \mathrm{~Hz}$ delivered at 200 msec intervals ( $\theta$ burst stimulation - TBS). It is known, that the 200 msec interval approximates the rate of exploratory sniffing in the rat, which corresponds to the limbic theta rhythm. After 5-10 min of the last tetanization the FPs were registered at the single LOT stimulation and then the NMDA-dependent LTD/LTD development was registered after LOT tetanization during $85 \mathrm{~min}$. We clarified the modification of postsynaptic excitatory components of FPs, at 45 min point after TBS of LOT. For these purposes, we registered and analyzed the AMPA and NMDA EPSPs amplitudes modifications in the phase of the LTP or LTD maintenance [29]. 


\section{Data analysis and statistics}

Statistical comparisons were performed with nonparametric Wilcoxon-MannWhitney $U$-test. Numerical data were expressed as mean \pm standard error of the mean (S.E.M.). The level of statistical significance was set at $p \leq 0.05$.

\section{RESULTS}

Recordings of excitatory postsynaptic components of FPs and analysis of LTP development in piriform cortex of slices after treatment with aODNs and sODNs

It has been revealed that the basic amplitude characteristics of FPs in piriform cortex were invariable during $6 \mathrm{~h}$ treatment of slices with as ODNs in response to LOT stimulation with frequency $0.003 \mathrm{~Hz}$, and the amplitudes of NMDA and AMPA EPSPs were equal to control values (Figures 1,2). Further the slices were exposured to "cognitive load" (LOT was tetanized by 10 sets of four pulses with frequency $100 \mathrm{~Hz}$ delivered at $200 \mathrm{msec}$ intervals,TBS). This stimulation led to modification of the AMPA EPSP amplitudes before and after TBS (AMPAR-dependent LTP) in control slices, indicated by the grey line; modification of the AMPA EPSP amplitudes before and after TBS in slices pretreated with sODNs or aODNs to GluN1subunit, indicated by black line. Horizontal dotted lines -the values of the AMPA EPSP before TBS. Thick up arrow (TBS)-LOT tetanization, after $6 \mathrm{~h}$ of the slices incubation in aCSF and aCSF with $10 \mathrm{nM}$ sODNs or aODNs for control and for treated slices, respectively. Vertical dashed line at 45 min noted the FPs demonstrated at figure $3 \mathrm{~B}$,C.The top panel corresponds to the phases of LTP development: I-phase of induction, II-phase of maintenance, III-phase of termination of LTP.

The NMDAR and AMPAR-dependent LTP in neurons. Three phases of the LTP development were identified in control nontreated slices. The short initiation phase with maximal amplitudes of NMDA and AMPA EPSPs. Then the long phase of maintenance with retained activity of these receptors was specified. At $70 \mathrm{~min}$ this phase transformed in phase of termination with declined amplitudes of synaptic responses (Figures 1,2).

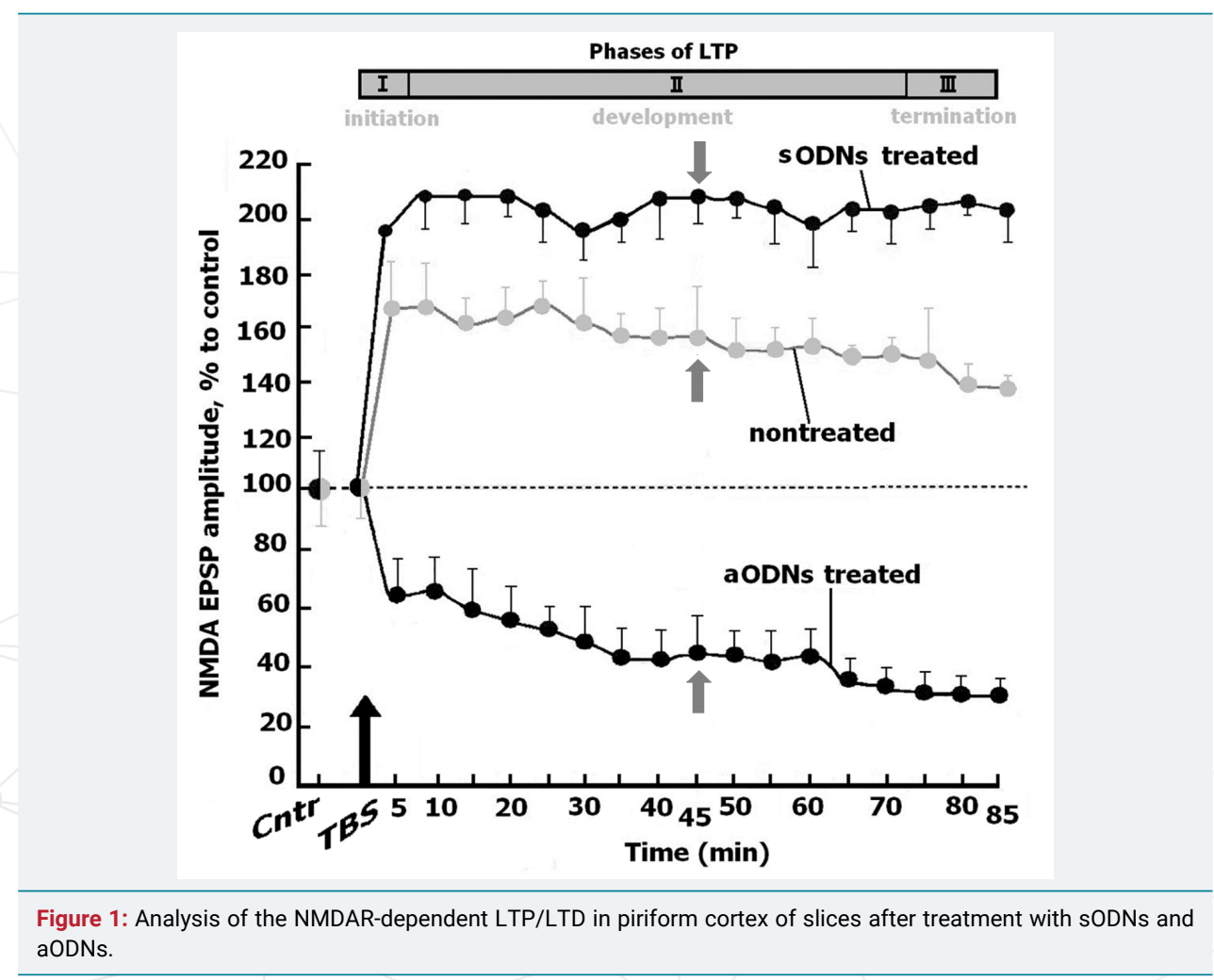




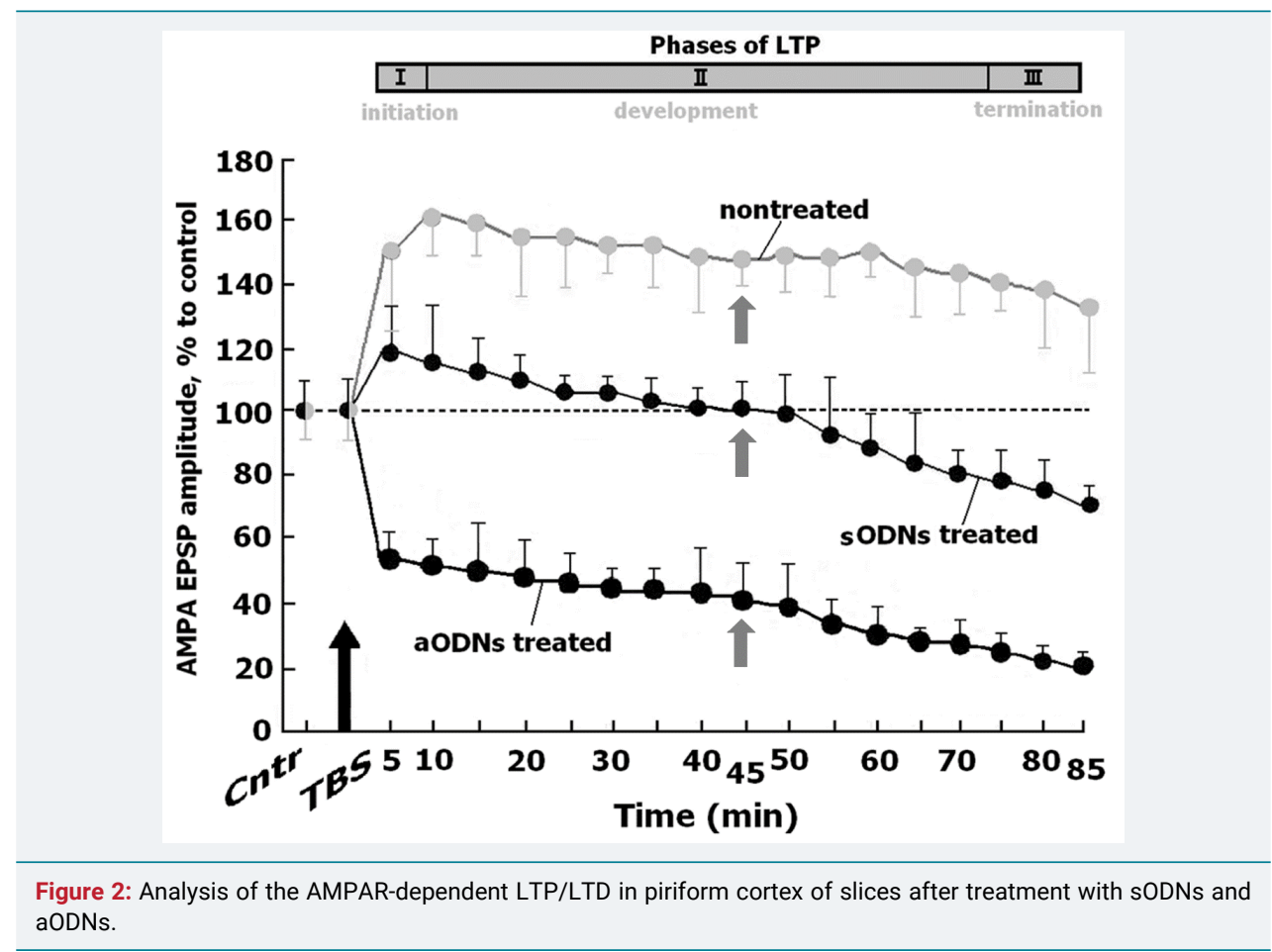

In slices treated with sODNs, TBS led to induction of quick initial phase of the NMDAR-dependent LTP. The amplitude of NMDA EPSP corresponded to this phase exceeded the control value although the differences were not significant $(191.0 \pm 8.0 \%$ vise verse $162.0 \pm 9.0 \%, U=38, n=11, p \geq 0.05$ ). The period of LTP maintenance was steady during all time of registration (85 $\mathrm{min}$ ).. The amplitudes of NMDA EPSP significantly enhanced compare with the control values $(210.0 \pm 15.0 \%$ versus control $158.0 \pm 9.0$ $\%, U=22, n=11, p \leq 0.05$ ). It is important that the phase of LTP maintenance prolonged in the treated slices, compared to the phase of LTP termination in nontreated slices (Figure 1). Treatment of slices with aODNs led to the decrease of the NMDA EPSP amplitude ( $40.0 \%$ of control, nontreated and nontetanized slices, $U=21, n=11, p \leq 0.05$ ). This decrease of NMDAR activity resulted in the LTD development.

The phases of initiation, maintenance and termination of the AMPAR-dependent LTP in control nontreated slices were similar to the same of NMDARs-dependent LTP ( $U=18, n=11, p \leq 0.05$, for each point). On the contrary, in slices treated with sODNs the AMPAR-dependent LTP slowly developed, terminated to $45 \mathrm{~min}$ and became transformed to LTD. This form of LTP is characteristic for short-term potentiation. Treatment of slices with aODNs at once led to the decrease of AMPA EPSPs and to the LTD development (Figure 2). The amplitudes of FPs in control nontreated slices were presented as traces of extracellular recordings (Figure 3A).

Analyzing these FPs after treatment with ODNs and TBS we focused on the time point of 45 min corresponding to a phase of LTP maintenance (Figure 1 and 2), the peak of NMDA and AMPA amplitudes marked as vertical dotted lines). In control nontreated slices, TBS resulted in significant increase of the AMPA and NMDA EPSP amplitudes (Figure 3B). The NMDA EPSP amplitude in the slices treated with sODNs has become still higher, while the amplitude of AMPA EPSP decreased (Figure 3C). We revealed that the slight increasing of latency of the maximal AMPA EPSP amplitude occurred in this time point possibly due to asynchronic activation of the AMPAR. The formation of the plateau between AMPA and NMDA components of FPs after TBS indicated that in these slices the permeability of AMPAR to $\mathrm{Na}^{+}$ions was inhibited (Figure $3 \mathrm{C}$ ). At the same time, the increase of the NMDA EPSP amplitude may be a result of the enhanced permeability of NMDAR to $\mathrm{Ca}^{2+}$ ions thereby prolonging the time of the LTP A: FPs in 
control- marked by grey line. AP LOT-total action potential of lateral olfactory tract of presynaptic events. Postsynaptic AMPA and NMDA components of FPs. The thin black line represents the trace of FPs under APV application $(50 \mu \mathrm{M})$ through A-C. Each FP (for A-C) is the result of summation of the five consecutive responses on the orthodromic single LOT stimulation with frequency $0.003 \mathrm{~Hz}$. The dash horizontal line-isoline, vertical lines indicate the peak of an amplitudes measuring for AMPA and NMDA EPSPs. Calibration (A-C) is as indicated. B: FPs in slices treated with sODNs under "cognitive load" - TBS, marked by grey line. Indications the same. C: FPs in slices treated with aODNs under "cognitive load" - TBS, marked by grey line. Taking together, these data convincingly pointed out the possibility of sODNs to act as cognitive enhancer. On the contrary aODNs decreased NMDA and AMPA EPSP amplitudes and promoted the induction of depressive potentiation. Phase of repolarization of AMPA component of FPs which reflected the outflow potassium current at that moment was found to be short ( $38.0 \%$ from the same of tetanized nontreated slices, $U=9, n=11, p \leq 0.05$ ). Amplitude of NMDA EPSP reduced significantly ( $41.0 \%$ from the same of nontreated slices without TBS, $U=10, n=11, p \leq 0.05$ ) (Figure 3C). The proportion of the slices with LTP after treatment with sODNs and aODNs under control (Cntr), oxygenated conditions and during 10 min anoxia. ${ }^{*} p \leq 0.05$ ( $U$-test of Wilcoxon-Mann-Whitney).

The TBS of LOT in control nontreated slices and in slices treated with sODNs induced NMDAR-dependent LTP in piriform cortex under normal oxygenation. In anoxic conditions (10 min) the irreversible blockade of the NMDAR activity in control nontreated slices took place (Figure 4). The treatment of slices with sODNs induced the significant changes in the NMDAR-dependent response to anoxia compared with control nontreated slices. Activity of NMDAR was unexpectedly protected even in conditions of severe anoxia. NMDAR activity were preserved within control values (75 $\%$ from control, $p \geq 0.05$ ) (Figure 4 ). Treatment with sODNs increased the proportion of potentiated slices with the LTP form of plasticity (Figure 4). It is interesting, the aODNs treatment decreased proportion of the slices with LTP, possibly, due to development of the LTD in slices. It may be the result of the shift to the prevailing depressive form of plasticity involving the majority of synaptic transmissions.

\section{DISCUSSION}

It is generally accepted that long-term synaptic changes such as synaptic plasticity and memory formation are associated with activation of glutamatergic synapses through the NMDAR-dependent ion channels [1,4-6,8,32-34]. This activity depends on assembly, activation and modulation of the different subunits of NMDARs [35-37].

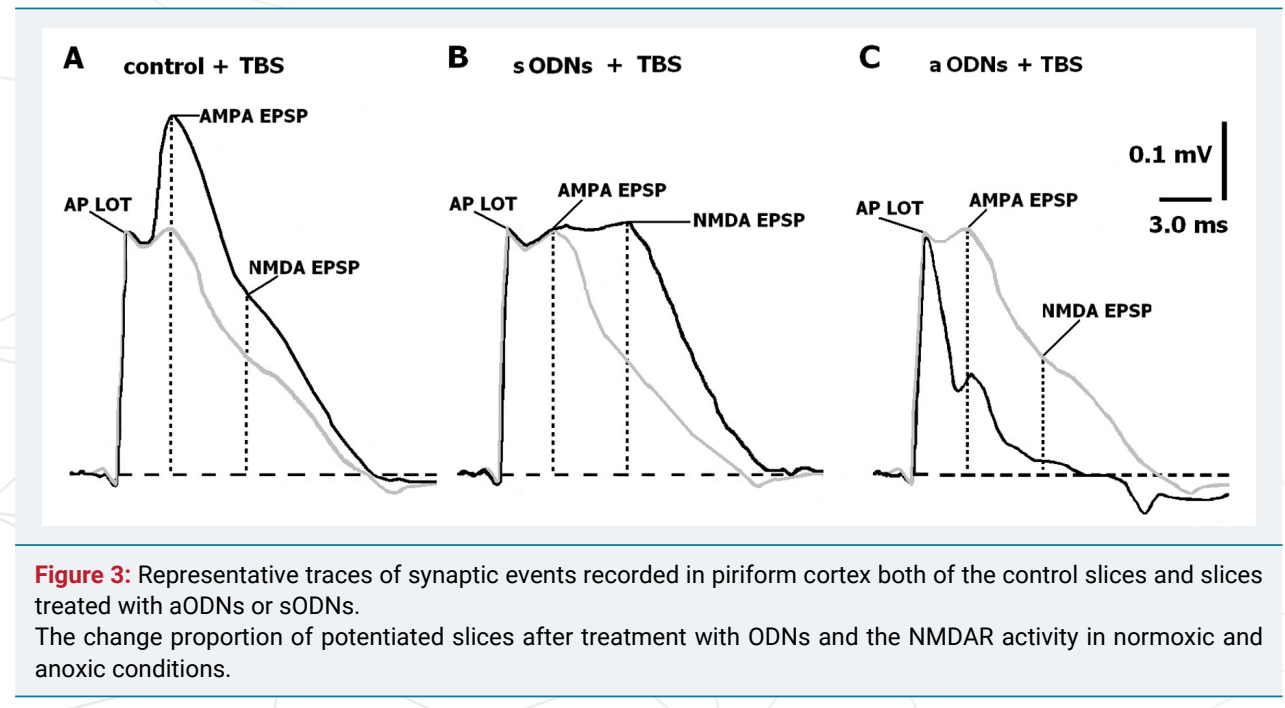


Our data have shown that the NMDARs and AMPAR-dependent long-term modification of synaptic plasticity readily developed in piriform cortex of slices after TBS. GluN1 subunit plays a main role in NMDAR functioning as an obligatory receptor subunit for receptor/channel function [1] and widely expresses in CNS [38-40]. It was shown that the rapid forms of NMDAR trafficking and the surface distribution of these receptors possibly regulated plasticity and modulate cognitive abilities [41-44]. We assumed that up- and down regulation of GluN1 subunit of these receptors may be involved in modification of synaptic plasticity in vitro. Indeed, when slices were treated with aODNs or sODNs the significant changes of the NMDARs and AMPAR-dependent LTP or LTD were determined. It should be point out that in slices treated with ODNs, without "synaptic loading" (low frequency, single impulse), which corresponded to a rest state of network, the baseline amplitude characteristics of FPs in slices were the same as in control, nontreated slices. It means that aODNs and sODNs did not changed neither excitability nor inhibition of synaptic network in olfactory slices.

On the contrary, after exposure of slices to "cognitive load" (high frequency LOT tetanization), which corresponded to long-term synaptic alterations in slices, the LTP or LTD development were depended of the applied ODNs. Our findings showed that aODNs promoted both NMDAR- and AMPAR-dependent LTD development in slices. It should be noted, that the aODNs affected both NMDA and AMPA component of FPs. These data may indicate that aODNs reinforced the efficacy of the synaptic glutamatergic activity. Such readjustment of the receptor activity is an essential component for controlling the excitation/inhibition balance in long-term prosesses of learning in brain. The similar interaction of NMDAR and AMPAR activity was shown previously in the cortical slice preparation [45]. The down-regulation of NMDAR activity by applied aODNs induced a reduction of the glutamatergic ionotropic receptor activity and corresponded to the data of protective action of these ODNs in hippocampal models in vitro $[14,20]$ and in vivo [17-19]. Similar protective effect was revealed on brain slices in our study. So, under the aODNs treatment an inhibition of NMDAR and significant decrease of the AMPAR activity was registrated (Figure 3C). We may concluded that such down regulation of the NMDAR activity resulted in lowered effect that may have protective potential for the harmful hyperactivation of the ionotropic glutamate receptors. Our findings showed that treatment of slices with aODNs led to preservation of their receptor mechanisms in anoxic conditions (Figure 4). It is consistent with the current knowledge of their role in the prossess of learning. Our data showed that a transient down regulation of GluN1 subunit in some cases resulted in protective lowering of NMDAR activity. At the same time prolonged hypofunction of this activity may have a negative influence. In the GluN1 knock-out models for investigation in schizophrenia the hypothesis of cognitive dysfunction is connected the permanent hypofunction of the NMDAR $[23-25,46]$.

It is interesting, that treatment of slices with sODNs directed to brief abundance of GluN1 subunit resulted in opposite effects. We showed that treatment of brain slices with sODNs significantly enhanced the NMDAR activity after "cognitive load" and promote the development both NMDAR- and AMPAR-dependent form of learning, as LTP. The amplitude of the NMDA component of FPs was almost equal to the same of the AMPA component (Figure 3C). It means that activity of these receptors are in the state of readiness for the favorable progression of learning. Indeed, the amplitudes of NMDA component and longitude of the potentiated state exceeded the control values. The AMPA component of FPs was activated in the phase of LTP initiation only. The state of LTP development was maintained due to the NMDAR activation. Thus, the treatment with sODNs induces enhancing effect on learning and possible on the forming of the memory traces. We supposed that such pharmacological processing resulted in improving of synaptic conductivity and eventually to facilitation of learning. These data are entirely consistent with contemporary view about the role of NMDARs in the processes of learning [12]. 


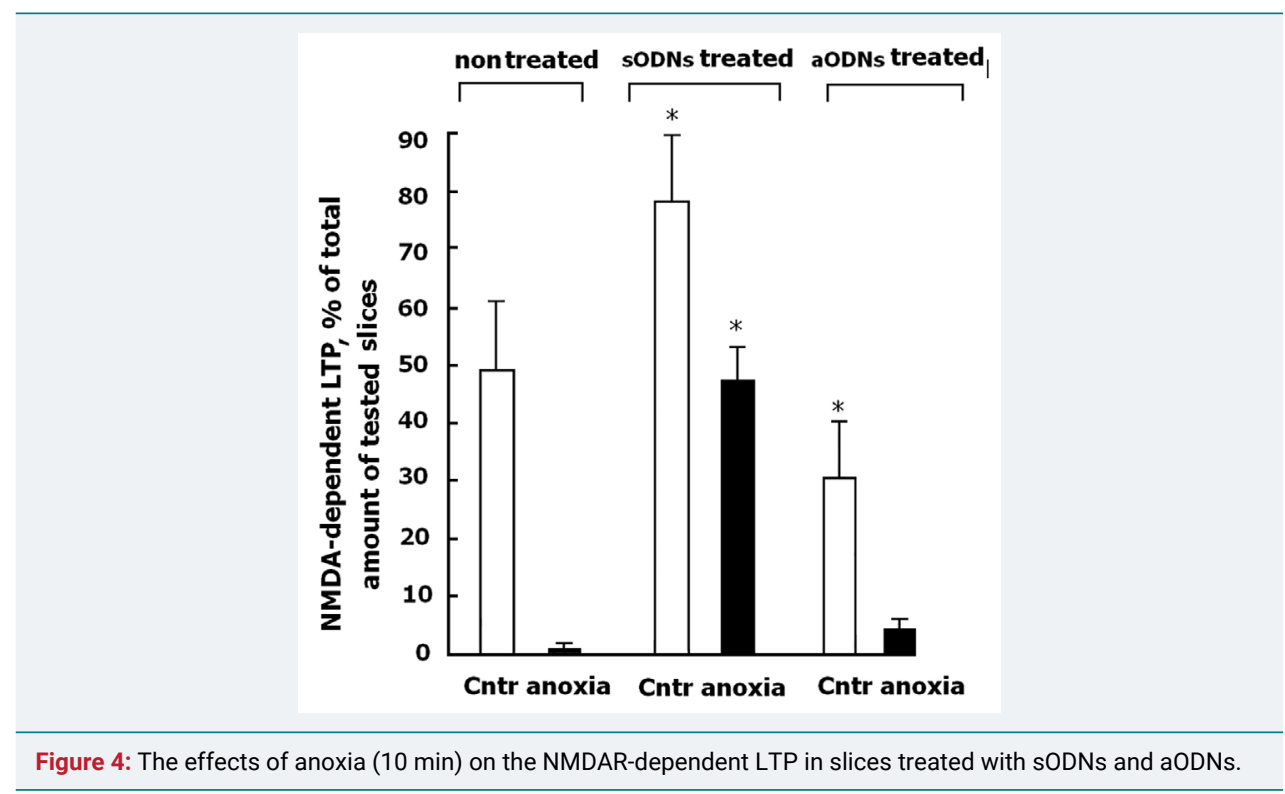

It is known, that inappropriate NMDAR activation is involved in the etiology of several diseases including acute strokes [47,48] and epilepsy [49]. We examined the role of up regulation of GluN1 in anoxic conditions too. It was established, that brain slices are very sensitive to insufficient oxygen supply in vitro [50]. Previously, we showed that severe $10 \mathrm{~min}$ anoxia induced irreversible blockade of NMDAR-mediated synaptic activity [51,52]. It is surprisingly, that the treatment of slices with ODNs promoted the preservation of activity of NMDAR in conditions of the acute oxygene deprivation of (Figure 4). The treatment of slices with sODNs led to cognitive-associated enhancing of LTP in the same conditions. Implications of GluN1 subunit in regulation of synaptic plasticity determined in our study demonstrate that sODNs may enhance non-associative form of the learning in piriform cortex acting as cognitive enhancer. This assumption possibly may be applicable even in case of damaging influence of severe anoxia.

\section{CONCLUSION}

The important pharmacological implications of the sODNs impact consisted in the positive influence on LTP development in the rat piriform cortex. Therefore, in practical implications a capability of sODNs to enhance the NMDAR-mediated synaptic plasticity should be taken into attention for coordination of the receptor activity as specific target in cure of cognitive processes in normal and certain pathological conditions as well as the protective ability of aODNs to suppress the excessive NMDAR activation.

\section{ACKNOWLEDGMENTS}

The authors thank Mrs. Galina Smirnova for her excellent technical assistance.

\section{REFERENCES}

1. Traynelis SF, Lonnie PW, Chris JMcB, Frank SM, Katie MV, et al. Glutamate receptor ion channels: structure, regulation, and function. Pharmacol Rev. 2010; 62: 405-496. Ref.: https://goo.gl/V74An8

2. Rebola N, Srikumar BN, Mulle C. Activity-dependent synaptic plasticity of NMDA receptors. J Physiol. 2010; 588 93-99. Ref.: https://goo.gl/7FgVTV

3. Paoletti P, Neyton J. NMDA receptor subunits: function and pharmacology. Curr Opin Pharmacol. 2007; 7: 39-47. Ref.: https://goo.gl/kEujvi

4. Cull-Candy SG, Leszkiewicz DN. Role of distinct NMDA receptor subtypes at central synapses. SciSTKE. 2004; 255 16. Ref.: https://goo.gl/ZhDLx7

5. Ulbrich MH, Isacoff EY. Rules of engagement for NMDA receptor subunits. PNAS. 2008; 105: 14163-14168. Ref.: https://goo.gl/xw2ZR8 
6. Salussolia CL, Prodromou M, Borker P, Wollmuth LP. Arrangement of subunits in functional NMDA receptors. J Neurosci. 2010; 31: 11295-11304. Ref.: https://goo.gl/KXPdRd

7. Cammarota M, De Stein ML, Paratcha G, Bevilaqua LR, Izquierdo I, et al. Rapid and transient learningassociated increase in NMDA NR1 subunitin the rat hippocampus. Neurochem Res. 2000; 25: 567-572. Ref.: https://goo.gl/TzCSPK

8. Bellone C, Nicoll RA. Rapid bidirectional switching of synaptic NMDA receptors. Neuron. 2007; 55: 779-785. Ref. https://goo.gl/pkNATy

9. Mahajan SS, Thai KH, Chen K, Ziff E. Exposure of neurons to excitotoxic levels of glutamate induces cleavage of the RNA editing enzyme, adenosine deaminase acting on RNA 2, and loss of GLUR2 editing. Neuroscience. 2011 25: 305-315. Ref.: https://goo.gl/svz56N

10. Wright A, Vissel B. The essential role of AMPA receptor GluR2 subunit RNA editing in the normal and diseased brain. Front Mol Neurosci. 2012; 5: 34-37. Ref.: https://goo.gl/NYri12

11. Weeber EJ, Sweatt JD. Molecular neurobiology of human cognition. Neuron. 2002; 33: 845-848. Ref. https://goo.gl/yDcD1g

12. Collingridge GL,Volianskis A, Bannister N, France G, et al. The NMDA receptor as a target for cognitive enhancement. Neuropharmacology. 2013; 64: 13-26. Ref.: https://goo.gl/EfERFG

13. Lai SK, Wong CKC, Yang MS, Yung KK. Changes in expression of N-methyl-D-aspartate receptor subunits in the rat neostriatum after a single dose of antisense oligonucleotide specific for $\mathrm{N}$-methyl-D-aspartate receptor onesubunit. Neuroscience. 2000; 98: 493-500. Ref.: https://goo.gl/SrvMmE

14. Lui PW, Yeung CW, Yung WH, Shi Y, Chen LW, et al. Ablation of Gene Expression of N-Methyl-D-Aspartate Receptor One by Antisense Oligonucleotides in Striatal Neurons in Culture. Neurosignals. 2005; 14: 303-316. Ref. https://goo.gl/SNDjAT

15. Standaert DG, Testa CM, Rudolf GD, Hollingsworth ZR. Inhibition of N-methyl-D-aspartate glutamate receptor subunit expression by antisense oligonucleotides reveals their role in striatal motor regulation. $\mathrm{J}$ Pharmacol Exp Ther. 1996; 276: 342-352. Ref.: https://goo.gl/vSdGQW

16. Lai SK, Ng TKY, Lau WK, Yang MS, Wong CKC, et al. Selective knock-down of gene expression of N-methyl-Daspartate receptor one ameliorates parkinsonian motor symptom in 6-hydroxydopamine-lesioned rats. Neurochem Int. 2004; 45: 11-22. Ref.: https://goo.gl/RerZ5L

17. Rydh-Rinder M, Berge OG, Hokfelt T. Antinociceptive effects after intrathecal administration of phosphodiester2'-allyl-, and C-5-propyne-modified antisense oligodeoxynucleotides targeting the NMDAR1 subunit in mouse. Mol Brain Res. 2001; 86: 23-33. Ref.: https://goo.gl/pCiGkk

18. Shimoyama N, Shimoyama M, Davis AM, Monaghan DT, Inturrisi CE. An antisense oligonucleotide to the N-methylD-aspartate (NMDA) subunit NMDAR1 attenuates NMDA- induced nociception, hyperalgesia, and morphine tolerance. J Pharmacol Exp Ther. 2005; 312: 834-840. Ref.: https://goo.gl/h4YJ8h

19. Xu A, Duan S, Zeng Y. Effects of intrathecal NMDA and AMPA receptor agonists or antagonists on antinociception of propofol. Acta Pharmacol Sinica. 2004; 25: 1-14. Ref.: https://goo.gl/mqV8i4

20. Lui PW, Yung KKL. Antisense knockdown of gene expression of NMDA receptor subunits in striatal neurons in culture. Soc Neurosci Abstr. 2001; 27: 2961-2965.

21. Cui Z, Wang H, Tan Y. Inducible and reversible NR1 knock-out reveals crucial role of the NMDA receptor in preserving remote memories in the brain. Neuron. 2004; 41: 781-793. Ref.: https://goo.gl/WAvru1

22. Belforte JE, Zsiros V, Sklar E, Jiang Z, Yu G, et al. Postnatal NMDA receptor ablation in corticolimbic interneurons confers schizophrenia-like phenotypes. Nat Neurosci. 2010; 13: 76-83. Ref.: https://goo.gl/k1XpFC

23. Rompala GR, Zsiros V, Zhang S, Kolata SM, Nakazawa K. Contribution of NMDA receptor hypofunction in prefrontal and cortical excitatory neurons to schizophrenia-like phenotypes. PLoS One. 2013; 8: 61278. Ref.: https://goo.gl/TXQgT6

24. Moy SS, Nikolova VD, Riddick NV, Baker LK, Koller BH. Preweaning sensorimotor deficits and adolescent hypersociability in Grin1 knockdown mice. Dev Neurosci. 2012; 34: 159-173. Ref.: https://goo.gl/sKRLy3

25. Milenkovic M, Mielnik CA, Ramsey AJ. NMDA receptor deficient mice display sexual dimorphism in the onset and severity of behavioural abnormalities. Genes Brain Behav. 2014; 13: 850-862. Ref.: https://goo.gl/qxo2Zh 
26. Grosshans DR, Clayton DA, Coultrap SJ, Browning MD. LTP leads to rapid surface expression of NMDA but not AMPA receptors in adult rat CA1. Nat Neurosci. 2002; 5: 27-33. Ref.: https://goo.gl/N9LUfH

27. Baez MV, Oberholzer MV, Cercato MC, Snitcofsky M, Aguirre Al, et al. NMDA receptor subunits in the adult rat hippocampus undergo similar changes after 5 minutes in an open field and after LTP induction. PLoS One. 2013 8: 55244. Ref.: https://goo.gl/5zyu3W

28. Henderson AK, Pittman QJ, Teskey GC. High frequency stimulation alters motor maps, impairs skilled reaching performance and is accompanied by an upregulation of specific GABA, glutamate and NMDA receptor subunits. Neuroscience. 2012; 215: 98-113. Ref.: https://goo.gl/idmGp7

29. Mokrushin AA. Peptide-dependent mechanisms of neural plasticity in olfactory cortex slices. Dissertation Doctor Sciences. Pavlov Institute Physiology Russian Academy of Sciences, Saint-Petersburg. Russia. 1997.

30. Wahlestedt C, Golanov E, Yamamoto S, Yee F, Ericson H, et al. Antisense oligodeoxynucleotides to NMDA-R1 receptor channel protect cortical neurons from excitotoxicity and reduce focal ischaemic infarctions. Nature. 1993, 363: 260-263. Ref.: https://goo.gl/nbgJdW

31. Mokrushin A, Pavlinova L. Hsp70 promotes synaptic transmission in the brain slices damaged by the contact with blood clot. Eur J Pharmacol. 2012; 677: 55-62. Ref.: https://goo.gl/1AV9Rx

32. Liu L,Wong TP, Pozza M, Lingenhoehl $\mathrm{K}$, Wang $\mathrm{Y}$, et al. Role of NMDA receptor subtypes in governing the direction of hippocampal synaptic plasticity. Science. 2004; 304: 1021-1024. Ref.: https://goo.gl/AtYDMR

33. Bloodgood BL, Sabatini BL. Regulation of synaptic signaling by postsynaptic, non-glutamate receptor ion channels J Physiol. 2008; 586: 1475-1480. Ref.: https://goo.gl/CjH5A7

34. Citri A, Malenka RC. Synaptic plasticity: multiple forms, functions, and mechanisms. Neuropsychopharmacology. 2008; 33: 18-41. Ref.: https://goo.gl/TWhNSM

35. Lei S, McBain CJ. Distinct NMDA receptors provide differential modes of transmission at mossy fiber-interneuron synapses. Neuron. 2002; 33: 921-933. Ref.: https://goo.gl/jjWree

36. Kohr G. NMDA receptor function: subunit composition versus spatial distribution. Cell Tissue Res. 2006; 326: 439446. Ref.: https://goo.gl/Lwc4Kr

37. Mayer ML. Structure and mechanism of glutamate receptor ion channel assembly, activition and modulation. Curr Opin Neurobiol. 2011; 21: 283-290. Ref.: https://goo.gl/aLqeHi

38. Zhong WX, Dong ZF, Tian M, Cao J, Xu L, et al. N-methyl-D-aspartate receptor-dependent long-term potentiation in CA1 region affects synaptic expression of glutamate receptor subunits and associated proteins in the whole hippocampus. Neuroscience. 2006; 141: 1399-1413. Ref.: https://goo.gl/orceEF

39. Alvarez VA, Ridenour DA, Sabatini BL. Distinct structural and ionotropic roles of NMDA receptors in controlling spine and synapse stability. J Neurosci. 2007; 27: 7365-7376. Ref.: https://goo.gl/N2ciGc

40. Simòes PF, Silva AP, Pereira F, Marques E, Grade S, et al. Methamphetamine induces alterations on hippocampal NMDA and AMPA receptor subunit levels and impairs spatial working memory. Neuroscience. 2007; 150: 433-441. Ref.: https://goo.gl/wRdQs2

41. Triller A, Choquet D. Surface trafficking of receptors between synaptic and extrasynaptic membranes: and yet they do move! Trends Neurosci. 2005; 28: 133-139. Ref.: https://goo.gl/PFXYza

42. Kopp C, Longordo F, Lüthi A. Experience-dependent changes in NMDA receptor composition at mature central synapses. Neuropharmacology. 2007; 53: 1-9. Ref.: https://goo.gl/dnYUxV

43. Bard L, Groc L. Glutamate receptor dynamics and protein interaction: lessons from the NMDA receptor. Mol Cell Neurosci. 2011; 48: 298-307. Ref.: https://goo.gl/fELEzw

44. Ladépêche L, Dupuis JP, Groc L. Surface trafficking of NMDA receptors: Gathering from a partner to another Semin. Cell Dev Biol. 2014; 27: 3-13. Ref.: https://goo.gl/rBmbGS

45. Roberts EB, Meredith MA, Ramoa AS. Suppression of NMDA receptor function using antisens DNA block ocular dominance plasticity while preserving visual responses. J Neurophysiol. 1998; 80: 1021-1032. Ref. https://goo.gl/vqJkgh

46. Gilmour G, Dix S, Fellini L, Gastambide F, Plath N, et al. NMDA receptors, cognition and schizophrenia-testing the validity of the NMDA receptor hypofunction hypothesis. Neuropharmacology. 2012, 62: 1401-1412. Ref. https://goo.gl/RUCFmc 
47. Machaalani R, Waters KA. Distribution and quantification of NMDA R1 mRNA and protein in the piglet brainstem and effects of intermittent hypercapnic hypoxia (IHH). Brain Res. 2002; 951: 293-300. Ref.: https://goo.gl/rypiZX

48. Cui H, Hayashi A, Sun HS, Belmares MP, Cobey C, et al. PDZ protein interactions underlying NMDA receptormediated excitotoxicity and neuroprotection by PSD-95 inhibitors. J Neurosci. 2007; 27: 9901-9915. Ref.: https://goo.gl/55XrmW

49. Toro CT, Hallak JE, Dunham JS, Leite JP, Sakamoto AC, et al. The NR1 N-methyl-D-aspartate subunit and brainderived neurotrophic factor in temporal lobe epilepsy hippocampus: a comparison of patients with and without coexisting psychiatric symptoms. Epilepsia. 2007; 48: 2352-2356. Ref.: https://goo.gl/Lp6KHW

50. MacGregor DG, Avshalumov MV, Rice ME. Brain edema induced by in vitro ischemia: causal factors and neuroprotection. J Neurochem. 2003; 85: 1402-1411. Ref.: https://goo.gl/EqtDir

51. Samoĭlov MO, Mokrushin AA. Peptide modulation of synaptic plasticity induced by anoxia. Dokl Akad Nauk. 1997; 357: 565-567. Ref.: https://goo.gl/LFZB9B

52. Samoilov MO, Mokrushin AA. The role of endogenous neuromodulator peptides in enhancement of the functional tolerance of brain neurons to anoxia. Biull Eksp Biol Med. 1998; 125: 503-505. Ref.: https://goo.gl/fqzj5b 